\title{
CHIRAL STANNANES FOR ASYMMETRIC SYNTHESIS
}

\author{
James A. Marshall \\ Department of Chemistry and Biochemistry, University of South Carolina, Columbia, \\ South Carolina 29208, USA
}

\begin{abstract}
Nonracemic $\alpha$-and $\gamma$-alkoxy and silyloxy allylic stannanes are easily prepared through reduction of acyl stannanes with chiral hydrides such as BINAL-H or Chirald followed by etherification of the hydroxy stannane products. The $\alpha$-isomers add to aldehydes to afford mainly syn adducts which can be converted to $\gamma$-lactones upon hydrolysis and oxidation. This reaction can be used to prepare cyclic adducts which serve as useful intermediates for the synthesis of cembrane natural products. With $\alpha$ chiral aldehydes, matched/mismatched pairing is observed. The stereochemical outcome is consistent with an acyclic Felkin-Ahn transition state. $\gamma$-Alkoxy stannanes show analogous reactivity. Additions to aldehydes lead to syn 1,2-diol derivatives. Matched/mismatched pairings are observed with $\alpha$-chiral aldehydes. The reaction is particularly useful as a method for carbohydrate chain extension.
\end{abstract}

\section{Introduction}

Allylmetal reagents have assumed an important role in modern organic synthesis. ${ }^{1}$ Of particular interest are $\alpha, \gamma$-disubstituted reagents which add to carbonyl components to afford homoallylic alcohols (eq 1 ). Such reactions can lead to mainly syn or anti products depending<smiles>[R]C=CC([R])[M]</smiles><smiles>[R]CC(=O)c1ccccc1</smiles>

upon reaction conditions and the nature of $M$. Reagents in which $\mathrm{M}=\mathrm{SnBu}_{3}$ or $\mathrm{SnMe}_{3}$, in contrast to those where $\mathrm{M}=$ e.g. $\mathrm{MgBr}, \mathrm{TiCl}_{3}, \mathrm{CrX}_{3}, \mathrm{SnX} \mathrm{X}_{3}$ and the like, are relatively stable and can be isolated, purified, and stored. ${ }^{2}$ One potential complication is the facile 1,3-isomerization of the foregoing reagents under reaction conditions conducive to addition. ${ }^{3}$ Thus, both stereoisomers and regioisomers can be formed as products. In the case of $R_{3} S n$ reagents, additions promoted by Lewis acids favor the syn adducts, regardless of double bond geometry, in

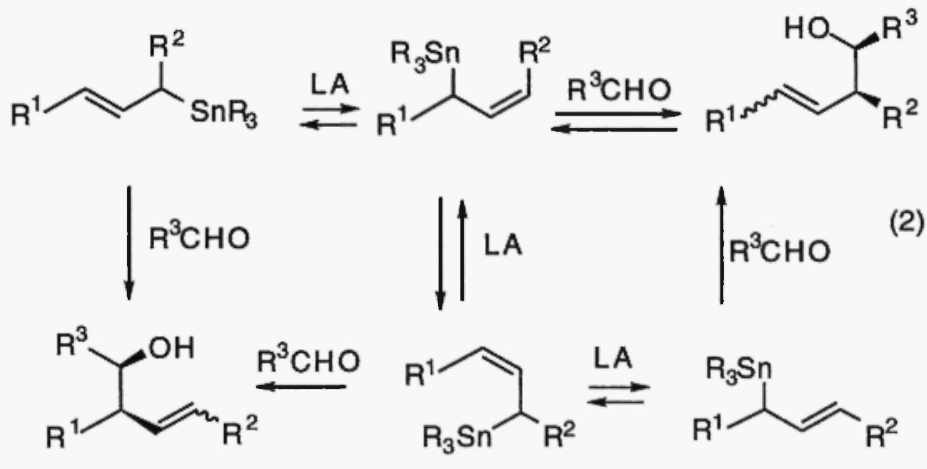

keeping with an acyclic transition state as first proposed by Yamamoto (eq 2). ${ }^{4}$ An additional complicating factor is the possible formation of $(E)$ and $(Z)$ double bond isomers. 
Allylic stannanes in which one of the substituents $\left(R^{1}, R^{2}\right)$ is alkoxy are of special interest. The $\alpha$-alkoxy isomers are readily prepared by addition of $\mathrm{Bu}_{3} \mathrm{SnLi}$ (or $\mathrm{Me}_{3} \mathrm{SnLi}$ ) to an enal followed by treatment with a reactive alkylating agent (eq 3). ${ }^{5,6}$ Attempts to alkylate the

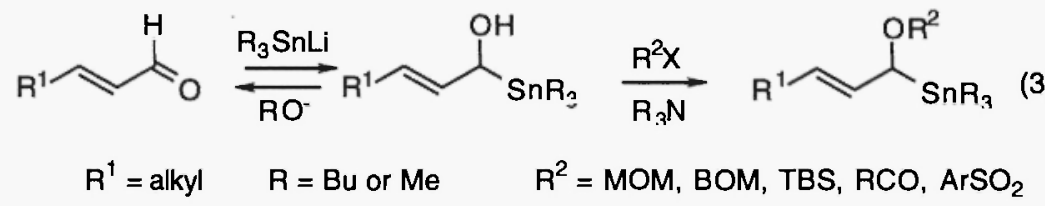

hydroxy stannane with less reactive alkylating agents $\left(\mathrm{CH}_{3} \mathrm{I}, \mathrm{CH}_{3} \mathrm{OTf}, \mathrm{CH}_{2}=\mathrm{CHCH}_{2} \mathrm{l}\right)$ requiring strong base (NaH, KHMDS, BuLi) leads to recovered enal through retrostannation. The intermediate lithio alkoxide adduct can be converted in situ to an $\alpha, \beta$-unsaturated acylstannane upon treatment with ADD or DIAD. ${ }^{6}$ Reduction with a chiral reducing agent, then alcohol protection, affords nonracemic $\alpha$-alkoxy allylic stannanes (eq 4). The use of Noyori's $(R)$-BINAL-

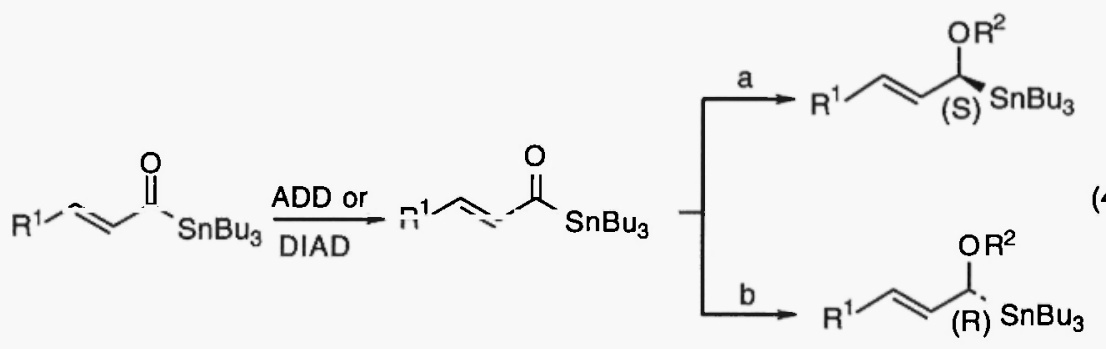

a) (R)-BINAL-H; $i \mathrm{Pr}_{2} \mathrm{NEt}, \mathrm{R}^{2} \mathrm{X}$; b) Chirald-LAH $(\rightarrow \sim 70 \%$ ee) or (S)-BINAL-H ( $\rightarrow \sim 95 \%$ ee); $1-\mathrm{Pr}_{2} \mathrm{NEt}, \mathrm{R}^{2} \mathrm{X}$.

$\mathrm{H}$ reagent leads to $(S)$ alkoxy stannanes of $>95 \%$ ee. ${ }^{7}$ The less expensive Chirald-LAH reagent of Mosher ${ }^{8}$ affords the $(R)$-enantiomers of $c a 70 \%$ ee whereas (S)-BINAL-H, as expected, gives products of $>95 \%$ ee.

Additions of the nonracemic $\alpha$-alkoxy allylic stannanes to aldehydes is stereospecific and generally quite stereoselective as illustrated in Table 1.6 Accordingly, the (S)-stannanes afford

Table 1. Addition of $\alpha$-Alkoxy Allylstannanes to Representative Achiral Aldehydes

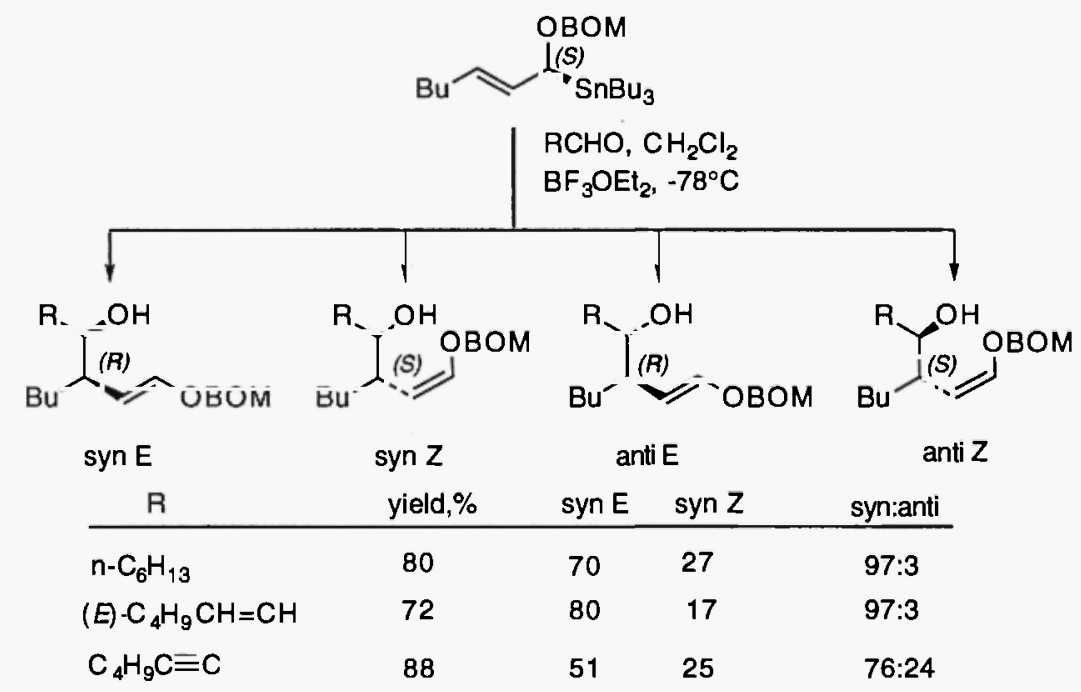


products in which the allylic center is $(R)$ in the $(E)$ and $(S)$ in the $(Z)$ product. The syn diastereomers are highly favored, though less so with alkynyl aldehydes, presumably for steric reasons. The major products of these additions are derived from transition states in which the alkyl groups $\left(R^{1}\right.$ and $R^{2}$ ) assume a preferred anti arrangement and the breaking $C-S n$ bond aligns anti periplanar to the forming $\mathrm{C}-\mathrm{C}$ bond (Figure 1).

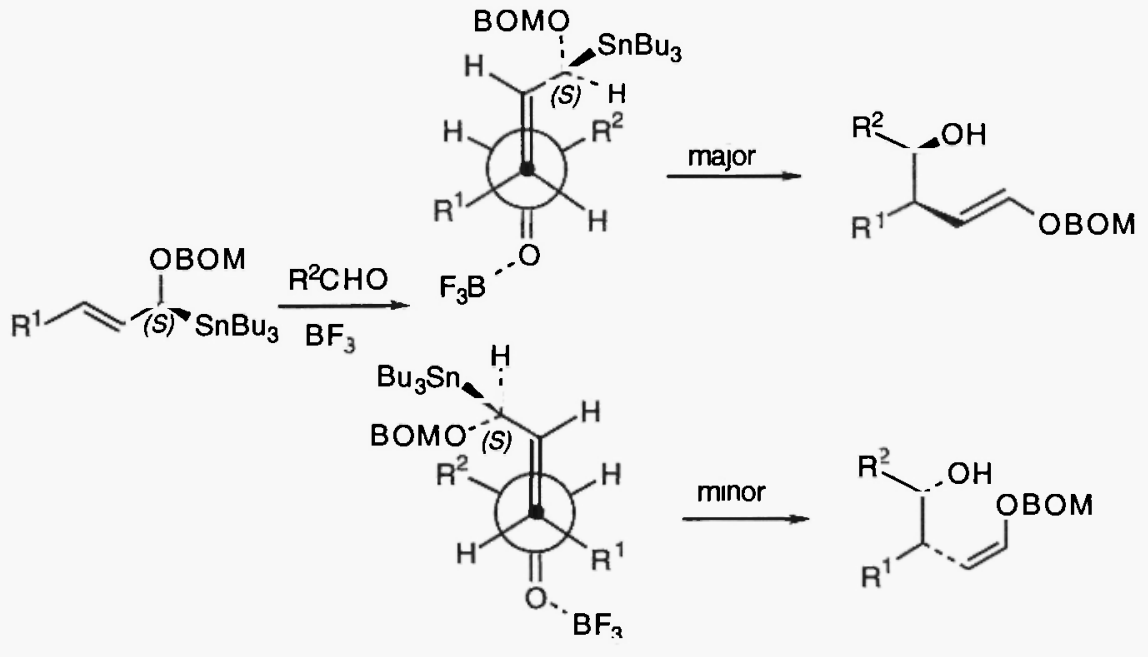

Figure 1. Transition states for $S_{E}$ additions of $\alpha$-alkoxy allylic stannanes

The reaction can be employed intramolecularly for the formation of macrocyclic alcohols. This methodology is well suited to the synthesis of cembrane lactones (eq 5). ${ }^{9}$

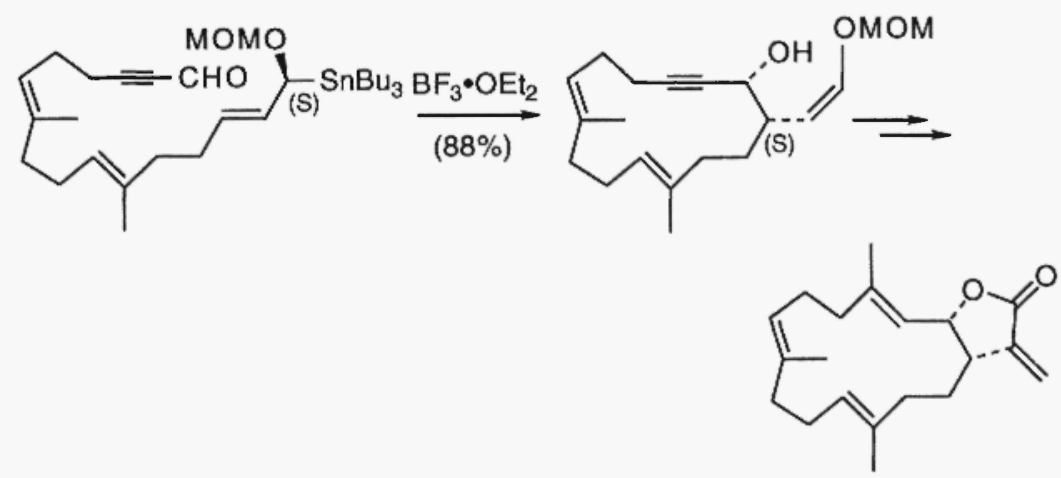

Macrocyclizations are also efficiently achieved with allenylstannanes as illustrated in eq 6. ${ }^{10}$ The homopropargylic alcohol products are readily converted to 2,5-furanocycles upon oxidation and isomerization. 11

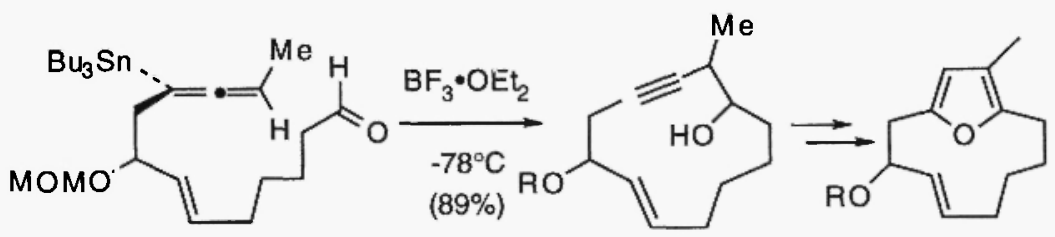

In the absence of a reactive aldehyde, $\alpha$-alkoxy allylic stannanes undergo stereospecific anti 1,3-isomerization with Lewis acids such as $\mathrm{BF}_{3} \cdot \mathrm{OEt}_{2}(\mathrm{eq} 7) .{ }^{6}$ The reaction affords $(Z) \cdot \gamma$ - 
$R^{1}$<smiles>[Z7]C=C[Si](O)([SiH2])[Se]CCCC</smiles><smiles>CCO[SbH2]</smiles>

$5 \mathrm{~min}$

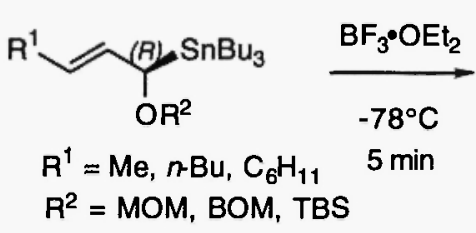

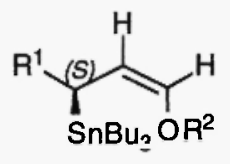

(7)

alkoxy stannanes exclusively, or nearly so. Silyloxy stannaries can be prepared from enals as shown in eq $8 .{ }^{12}$ In this case, the $\alpha \rightarrow \gamma$ isomerization can also be effected by TBSOTf, $\mathrm{Bu}_{3} \mathrm{SnOTf}$, and 3-5 $\mathrm{M} \mathrm{LiClO}_{4}$ in $\mathrm{Et}_{2} \mathrm{O}$.

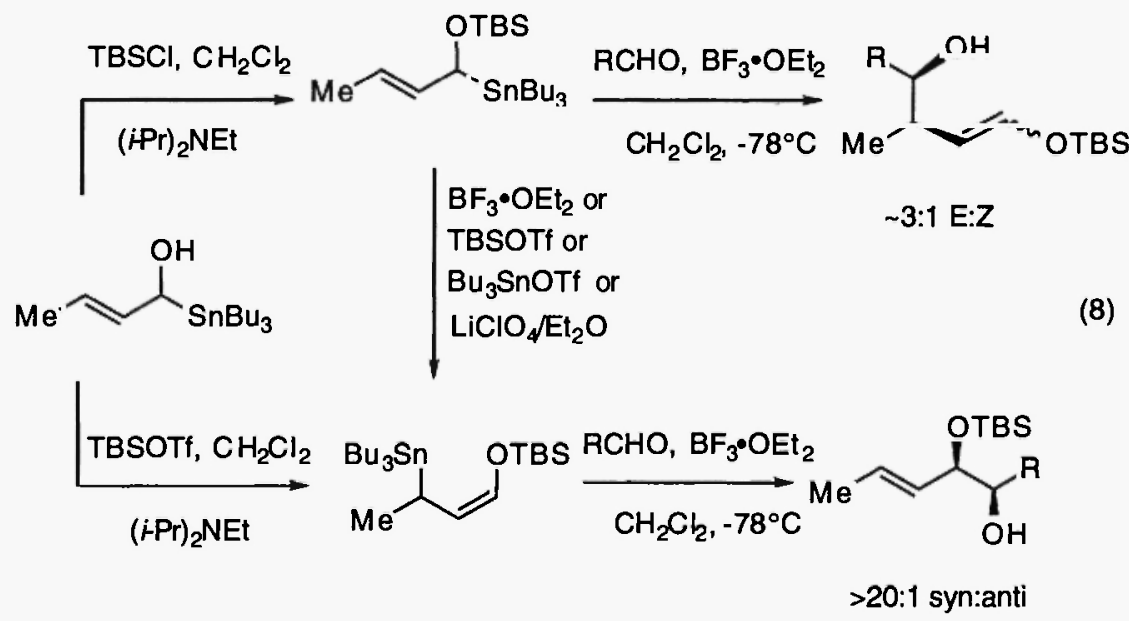

(E)- $\gamma$-Silyloxy allylic stannanes are obtained by 1,4 -addition of a Lipschutz higher order $\mathrm{Bu}_{3} \mathrm{Sn}$ cuprate to an enal followed by trapping of the enolate with $\mathrm{TBSCl}$ (eq 9). ${ }^{13}$

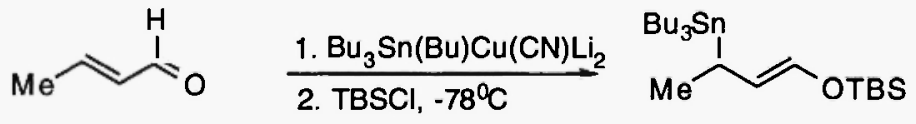

Both (Z)- and $(E)$ - $\gamma$-silyloxy stannanes add to aldehydes in the presence of $\mathrm{BF}_{3} \cdot \mathrm{OEt}_{2}$ to afford mainly syn 1,2-diols. As can be seen from Table II, the (E)-stannanes are particularly diastereoselective. 
Table 2. Addition of (E)- and (Z)- $\gamma$-Alkoxy Allylstannanes to Aldehydes

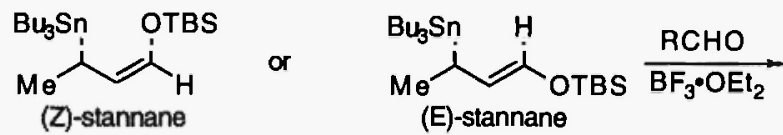<smiles>[R]C(O)C(O)C(=O)OC</smiles>

syn<smiles>[R]C(O)C([OH+])/C=C/C</smiles>

anti

\begin{tabular}{lccc}
\multicolumn{1}{c}{ R } & \multicolumn{2}{c}{ yield,\% } & \multicolumn{2}{c}{ (E)-stannana } & $(Z)$-stannane \\
\hline $\mathrm{n}-\mathrm{C}_{6} \mathrm{H}_{13}$ & 89 & $>99: 1$ & $97: 3$ \\
$(E)-\mathrm{C}_{4} \mathrm{H}_{9} \mathrm{CH}=\mathrm{CH}$ & 84 & $>99: 1$ & $>99: 1$ \\
$\mathrm{C}_{4} \mathrm{H}_{9} \mathrm{C} \equiv \mathrm{C}$ & 84 & $>99: 1$ & $93: 7$ \\
$c-\mathrm{C}_{6} \mathrm{H}_{11}$ & 79 & $>99: 1$ & $94: 6$
\end{tabular}

As a measure of relative reactivity, pairs of allylic stannaries were allowed to react with limited cyclohexenecarbaldehyde in the presence of $\mathrm{BF}_{3} \cdot \mathrm{OEt}_{2}$ under controlled conditions (stannane 1: stannane 2: aldehyde: $\mathrm{BF}_{3} \cdot \mathrm{OEt}_{2}=1: 1: 1: 1$ ). Product ratios and, where possible, recovered stannane, were measured by $\mathrm{GC}$ analysis and/or ${ }^{1} \mathrm{H}$ NMR integration. The following order was found (Fig 3):

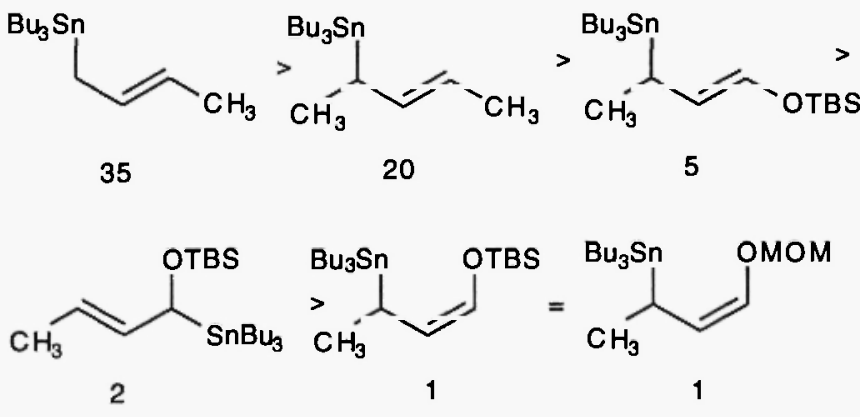

Figure 3. Relative reactivity of allylic stannanes toward $c-\mathrm{C}_{6} \mathrm{H}_{11} \mathrm{CHO}$

Thus, alkoxy and, to a lesser extent, alkyl substitution tends to lower the reactivity of the allylic stannane. However, the effect is modest, at best.

\section{Results and Discussion}

$\alpha$-Alkoxy allylic stannanes show double diastereoselection in additions to $\alpha$-chiral aldehydes as exemplified in eq 10.14,15 The observed selectivity is understandable from the Felkin-Ahn and Yamamoto transition state models for the addition. In mismatched additions, adducts resulting from the isomerized $\gamma$-alkoxy allylic stannanes are often isolated, in keeping with the lesser reactivity of the aldehydes towards the $\alpha$-isomers. An extreme case in point is shown in eq 11 wherein the mono protected 1,2-diol is the exclusive product from an attempted intramolecular $\alpha$-alkoxy allylic stannane cyclization (eq 11). ${ }^{16}$ 


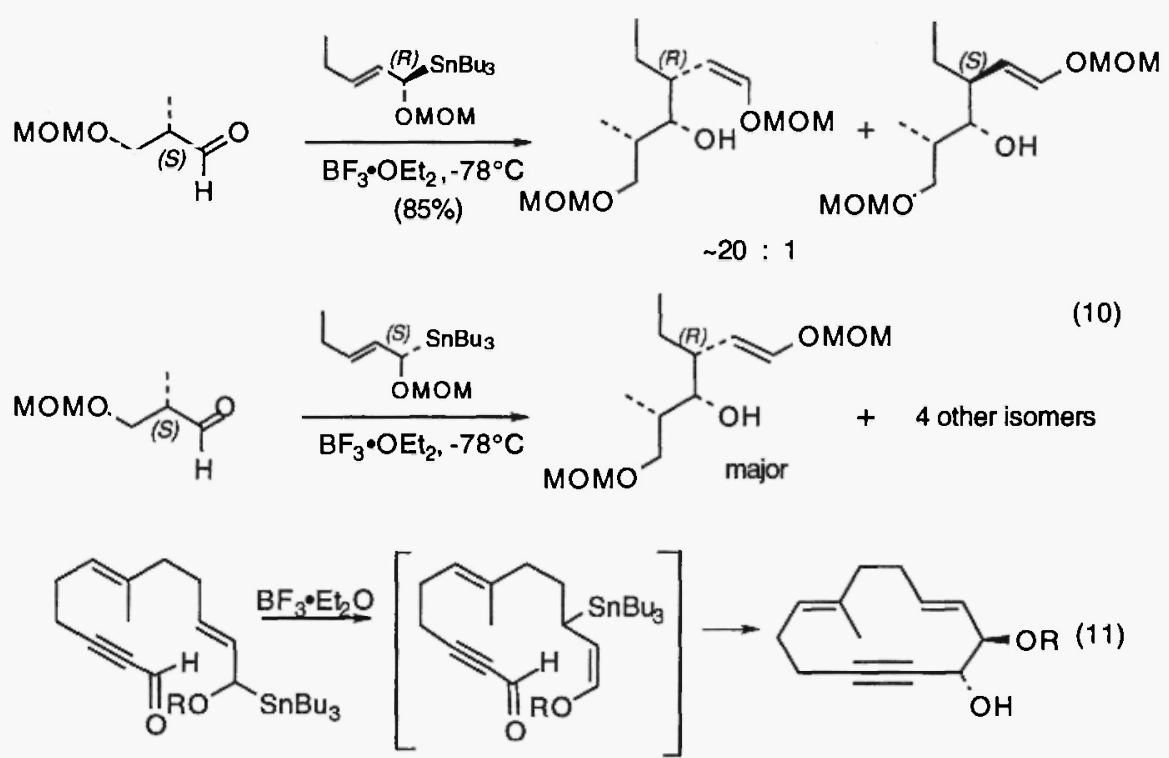

The intermolecular addition has been used to synthesize macrolide precursors, as illustrated in eq 12.15 In this case, a single adduct was isolated, indicative of highly favorable matching of stannane and aldehyde.

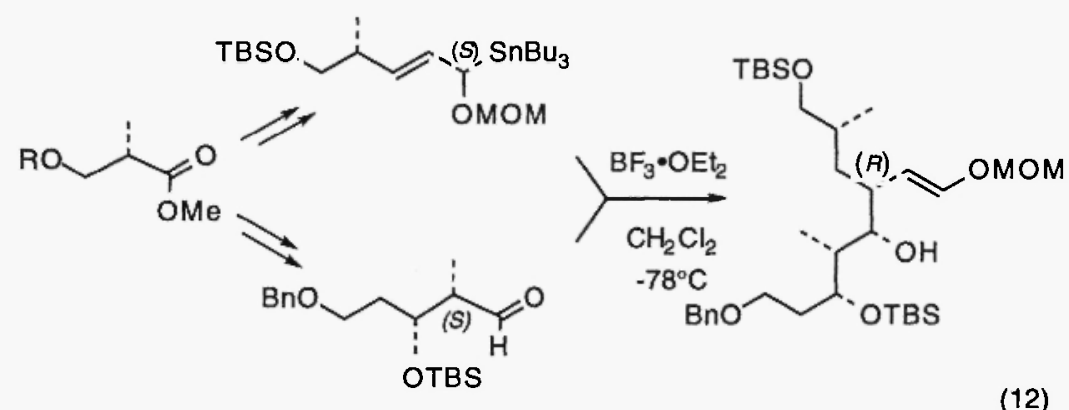

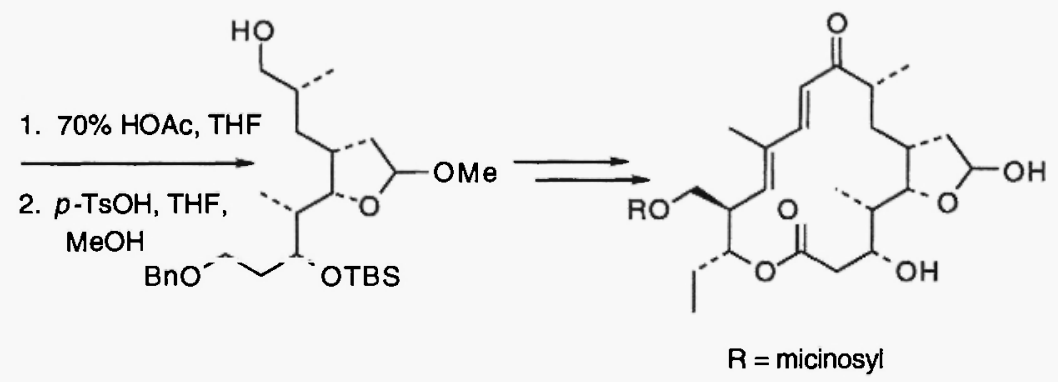

The addition of $\gamma$-alkoxy allylic stannanes to $\alpha$-alkoxy aldehydes leads to monoprotected syn 1,2-diols with high stereoselectivity. ${ }^{14}$ The absolute configuration of these products is reagent dependent. The acetogenins $(-)$ and $(+)$-muricatacin proved suitable targets for this methodology (eq 13). ${ }^{17}$ 


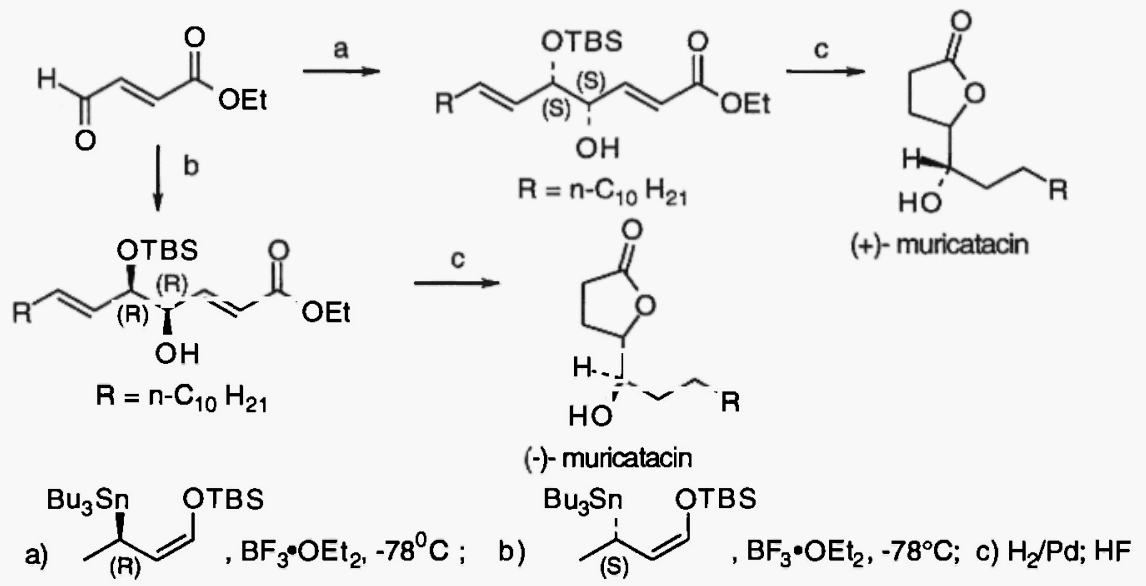

The diene diol derivatives obtained from additions of $\gamma$-silyloxy allylic stannanes to enals can be further transformed through hydroxylation of the double bonds to $\omega$-deoxy sugar derivatives. The bis-TBS derivatives show high anti selectivity in these conversions (eq 14).

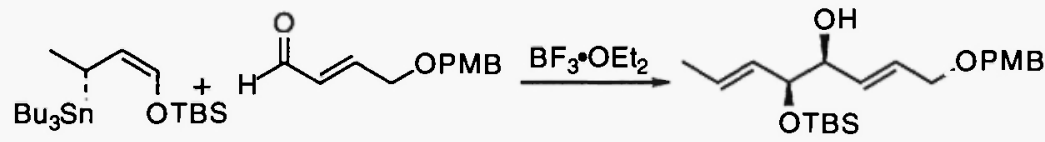

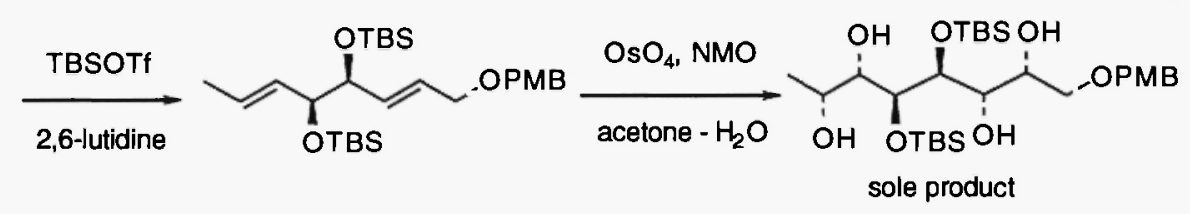

Addition to suitably protected carbohydrates and other $\alpha$-alkoxy aldehydes provides an alternative method for carbohydrate elaboration as illustrated in eq $15 .^{14}$ With these systems, $\mathrm{MgBr}_{2}$ can be used as the Lewis acid. The additions take place through a chelated

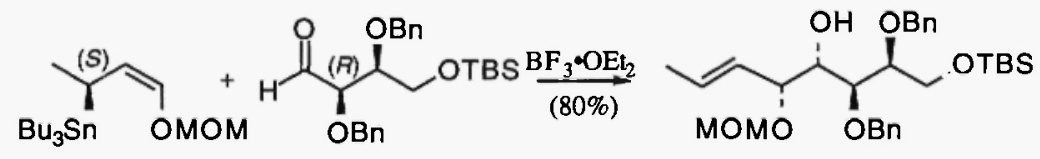

aldehyde and provide for pairing of aldehyde and stannane component complementary to that of $\mathrm{BF}_{3} \cdot \mathrm{OEt}_{2}$ (eq 16).
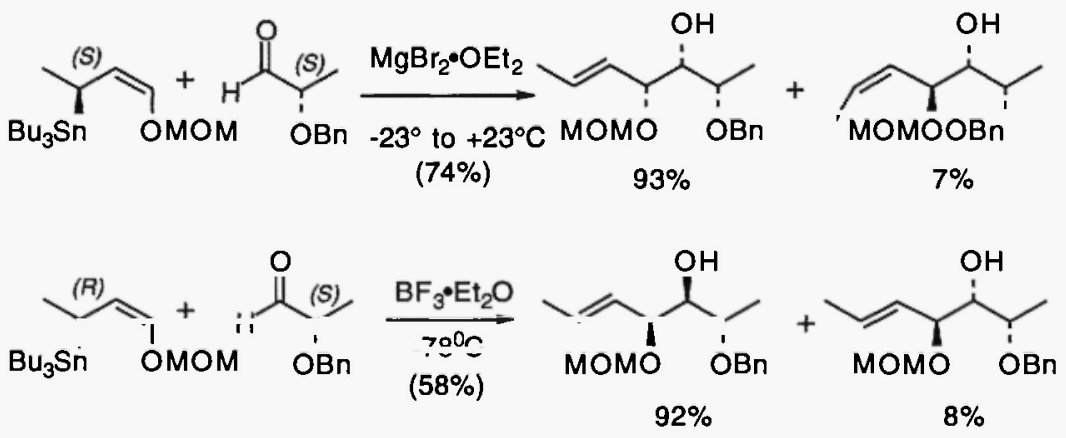
It is also possible to access higher carbohydrates through chain extension of readily available lower homologues, as illustrated in eq 17.

(D)-glucose<smiles>O=CC(Cc1ccccc1)[C@H](O)[C@@H](O)C(Cc1ccccc1)C(Cc1ccccc1)Cc1ccccc1</smiles>

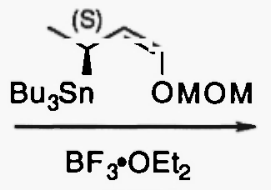

(98\%) 18). ${ }^{18}$

The $\mathrm{MgBr}_{2}$ promoted addition has been used in an efficient synthesis of bengamide $\mathrm{E}$ (eq<smiles>COC(=O)C(C(=O)OC)C(OC)C(=O)O</smiles><smiles>COC(=O)C(OC)C(OC)C(O)C(O)C(C=CC(C)C)O[Na]</smiles>

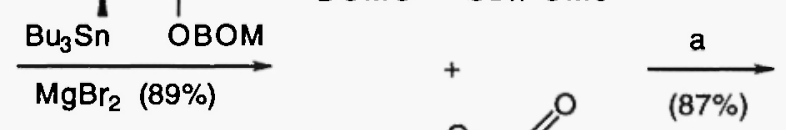<smiles>COC(=O)C(C=CC(C)C)C1OC(=O)C(OC)C1OCc1ccccc1</smiles>

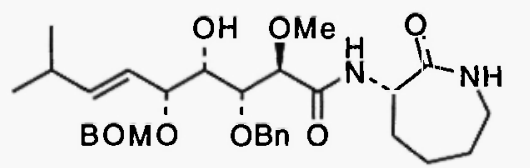<smiles>[Mg][Mg][Mg]</smiles><smiles>COC(C(=O)NC1CCCCNC1=O)C(O)C(O)C(O)/C=C/C(C)C</smiles>

Bengamide $E$

a)<smiles>NC1CCCCNC1=O</smiles>

Conclusions: The foregoing examples illustrate the potential of nonracemic $\alpha$ and $\gamma$-alkoxy allylic stannanes in synthesis. These reagents are particularly effective in macrocyclizations and acyclic chain elongation. Product stereochemistry can be predicted with a high degree of certainty when the stannane configuration is known. With $\alpha$-alkoxy aldehyde substrates, complementary stereochemical results can be realized through proper choice of Lewis acid. $\mathrm{MgBr}_{2}$ leads to syn, syn adducts through a chelation controlled transition state whereas $\mathrm{BF}_{3}$ affords syn, anti products by way of a Felkin-Ahn transition state. The use of $\gamma$-alkoxy allylic stannanes in these additions provides a convenient method for carbohydrate synthesis and chain elongation.

Acknowledgments: Funding for this research was provided by Grant R01-Al 31422 from the National Institute of Allergy and Infectious Diseases. 


\section{References}

1. Roush, W.R. in Comprehensive Organic Synthesis. Vol 2, Trost, B.M., Ed. Pergamon Press, 1991, pp 1-53. Fleming, I. in Comprehensive Organic Synthesis, Vol 2, Trost B.M., Ed. Pergamon Press, 1991, pp 563-593.

2. Yamamoto, Y. Aldrichimica Acta 1987, 20, 45. Pereyre, M.; Quintard, J-P.; Rahm, A. Tin in Organic Synthesis. Butterworth, London, 1987, pp 211-230. Marshall, J.A. Chemtracts - Organic Chemistry 1992, 75.

3. Denmark, S.E.; Wilson, T.; Willson, T. J. Am. Chem. Soc. 1988, 110, 984.

4. Yamamoto, Y.; Yatagai, H.; Ishihara, Y.; Malda, N.; Maruyama, K. Tetrahedron 1984, 40, 2239.

5. Still, W.C. J. Am. Chem. Soc. 1978, 100, 1481.

6. Marshall, J.A.; Welmaker, G.S.; Gung, B.W. J. Am. Chem. Soc. 1991, 113, 647.

7. Noyori, R.; Tomino, I.; Tanimoto, Y.; Nishizawa, M. J. Am. Chem. Soc. 1984, 106, 6709.

8. Yamaguchi, S.; Mosher, H.S. J. Org. Chem. 1973, 38, 1870.

9. Marshall, J.A.; Gung, W.Y. Tetrahedron Lett. 1988, 29, 3899.

10. Marshall, J.A.; Wang, X-j. J. Org. Chem. 1991, 56, 6264.

11. Marshall, J.A.; Wang, X-j. J. Org. Chem. 1992, 57, 3387.

12. Marshall, J. A.; Welmaker, G.S. Tetrahedron Lett. 1991, 32, 2101.

13. Marshall, J.A.; Welmaker, G.S. . J. Org. Chem. 1992, 57, 7158.

14. Marshall, J. A.; Luke, G.P. J. Org. Chem. 1991, 56, 483.

15. Marshall, J.A.; Yashunsky, D.V. J. Org. Chem. 1991, 56, 5493.

16. Marshall, J.A.; Gung, W.Y. Tetrahedron Lett. 1989, 30, 309.

17. Marshall, J.A.; Welmaker, G.S. Synlett, 1992, 537.

18. Marshall, J.A.; Luke, G.P. Synlett 1992, 1007.

Received: July 27, 1993 
